industrially undeveloped countries, but they are handicapped by the heavy capital expenditure. The world demand for nitrogen fertilizers in 1960 61 is expected to be $8 \cdot 1$ million tons, of which Europe and the United States will together use 5.5 million tons. Prof. Dhar emphasized the desirability of building up phosphate reserves in the soil because natural fixation of atmospheric nitrogen in the soil is increased by adequate supplies of phosphate. Nitrogen is the key element in crop production; it is calculated that $100 \times 10^{6}$ tons of nitrogen are necessary for producing the world's food materials, excluding grass; but the chemical industry at present produces only $7 \times 10^{6}$ tons and legumes $5 \times 10^{6}$ tons. The nitrogen requirement of the world's grassland is estimated at $155 \times$ $10^{6}$ tons per annum, so that of the $250 \times 10^{6}$ tons of nitrogen necessary for the production of the major food crops of the world only 3 per cent comes from artificial fertilizers, 2 per cent from legumes, 2-3 per cent from precipitation and 2 per cent from organic manures. The rest is produced in the soil by microbiological activity on organic matter. Thus, industrial nitrogen supplies only a small part of the nitrogen requirement of crops, and a great deal can be done to increase land fertility by the better use of organic material supplemented by phosphate fertilizers to increase natural nitrogen fixation.

\section{New Zealand Phytochemical Survey}

During a survey of the New Zealand native flora for possible tumour inhibitory principles, extracts have been examined for the presence of alkaloids, leucoanthocyanins, saponins and triterpenes or steroids. In the latter work numerous fresh plants which are not extracted in bulk, and also herbarium specimens from the Auckland Institute and Museum, have been examined. The results of testing the New Zealand gymnosperms have now been reported (N.Z. J. Sci., 4, No. 1; March 1961). The investigations show that alkaloids are not commonly found in species of the gymnosperms, notable exceptions being ephedrine from Ephedra species and taxine from Taxus baccata. No species of the New Zealand Cupressaceae or Podocarpaceae were found to contain alkaloids, but the heartwood of the sole representative of the Pinaceae, Agathis austalis, was found to give positive tests. The presence of an alkaloid has been afterwards confirmed when bulk samples of the heartwood were extracted and a water-insoluble alkaloidal fraction isolated in low yield. Attempts to isolate a pure compound have been unsuccessful. All the species gave positive tests for leucoanthocyanins, the barks of the plants being the richest source of these compounds. The isolation of the principle leucoanthocyanin from the bark of Dacrydium cupressinum has already been reported and has been shown to be a stereoisomer of leucocyanidin which is apparently not identical with any isomer previously isolated. That from the bark of Dacrydium biforme has also been isolated by one of the investigators but has not been obtained pure. It differs from that of D. cupressinum, giving delphinidin on hydrolysis.

\section{Data on Research and Development}

A PRELIMINARY report issued by the National Science Foundation (Reviews of Data on Research and Development, No. 28; June 1961. $N S F^{7} 61-31$ ) gives the capital expenditure of colleges and universities in the United States for research and development in the natural and social sciences in 1958 as 153.5 million dollars, of which 112 million dollars came from non-Federal sources. The remainder came from the Federal Government, being largely confined to the large research centres which colleges and universities administer for the Federal Government. Half this expenditure was in the biological sciences, 33 per cent in the physical sciences, 15 per cent in the engineering, and 3 per cent in the social sciences.

\section{J.L.T. Industrial Research Fellowships}

J. LANGHAM THOMPSON, LTD., are introducing a scheme of fellowships for young research workers, normally on a two-year tenure, with the intention that those appointed should carry out their research in the Company's laboratories in Watford, Hertfordshire. The fields of interest to the Company include: solid state, cybernetics, logical systems, electronics, circuit techniques, micro-waves, mechanics of solids, transducer techniques, optics. Candidates for these fellowships should have completed a higher degree, or have carried out original research of a high standard and have a clear appreciation of the research programme they wish to pursue. Further information can be obtained from J. Langham Thompson, Ltd., 176 High Road, Bushey Heath, Hertfordshire.

\section{Sixth International Mineral Processing Congress}

THE sixth International Mineral Processing Congress will be held in Cannes during May 26-June 1, 1963. Organization is in the hands of la Société de l'Industrie Minérale and the following executive committee has been appointed: President, M. R. J. Testut; General Secretary, M. Pierre Gy; Members, MM. Astier, Emery, Ploix, Rey, Saint-Guilhem, Saverot, Seyer, Vielledent and Vuchot. As in the past, this Congress will be concerned with all aspects of mineral processing, and papers will be selected entirely on the basis of their scientific and technical value. However, the Committee wishes to place particular emphasis on the following subjects: (1) the concentration of iron minerals, including magnetic roasting but excluding agglomeration; (2) measurement, control and automation; (3) hydrometallurgy. Especial importance is also attached to the economic aspects of mineral processing and it is hoped that, whenever possible, authors will include data on installation and operating costs and comparative costs for alternative processes. The official languages of the Congress will be French, English, Russian and German, and provision will be made for simultaneous translation of discussions. An extensive series of visits to mineral processing plants and laboratories in Mediterranean countries will be arranged. The representative for the United Kingdom and the British Commonwealth is Prof. M. G. Fleming, Royal School of Mines, Prince Consort Road, London, S.W.7, to whom abstracts must be sent by October 15,1961 .

\section{University News :}

Birmingham

Prof. William Henry Trethowan, professor of psychiatry in the University of Sydney, has been appointed to the chair of psychiatry; the date will be arranged.

Edinburgh

THE following appointments have been announced: Imperial Chemical Industries Research Fellows, Juris Reinfelds (Adelaide) and Imre Laszlo (Debrecen), 